\title{
Integrating Computer Mediated with Face-to-face Communication and EFL Learners' Vocabulary Improvement
}

\author{
Abbas Ali Rezaee \\ Faculty of Foreign Languages and Literatures, University of Tehran (UT), Iran \\ Email: aarezaee@ut.ac.ir \\ Solmaz Ahmadzadeh \\ Faculty of Foreign Languages and Literatures, University of Tehran (UT), Iran \\ Email: solmaz.ahmadzade@gmail.com
}

\begin{abstract}
Studies in Computer Mediated Communication (CMC) have shown its potentiality to help enhance language learning. The present study investigates the effects of integrating synchronous and asynchronous CMC with Face-to-Face Communication (FFC) on vocabulary improvement among EFL learners. The 88 participants of the study were divided into one comparison, FFC, and two experimental, CMC and Integrated CMC (ICMC), groups. Two tests and a questionnaire were administered for collecting the data. The results revealed that the students in the comparison group had no significant improvement in their vocabulary scores. In contrast, both experimental groups did much better in the post-test. The results implied that the ICMC group outperformed the CMC one, meaning the superiority of the ICMC group over the other groups.
\end{abstract}

Index Terms - Computer Mediated Communication (CMC), synchronous, asynchronous, email, blog, chat

\section{INTRODUCTION}

Nowadays, computers have become an inseparable part of everybody's life. By far, their roles in education, especially in language learning and teaching, have expanded so drastically that no language instruction can ignore them in its curriculum. With the advent of the internet, as Warschauer and Healey (1998) believe, the role of computers as a tool for information processing and display has changed into a tool for information processing and communication. Not only can the internet be used to develop access to resources, it is also used to enhance communication between individuals and groups (Levy, 1997). Computer Mediated Communication (CMC) has been considered as a facilitator in developing communication among learners themselves and between learners and instructors, thereby the processes of language teaching and learning have, to a large extent, improved.

Herring (1996, p. 1) defines CMC as "communication that takes place between human beings via the instrumentality of computers." With the help of CMC and the internet, learners of a language can communicate quickly with other learners or speakers of the target language all over the world. This communication can be either synchronous, i.e., when all users are logged on and chat at the same time or asynchronous, that is, when a delayed message system such as electronic mail is the medium of communication. In order to benefit from these innovations, many studies have been conducted. On the other hand, learners feel more at home when teachers are mostly willing to develop a Face to Face Communication (FFC) with them. Therefore, it seems necessary to investigate whether integrating CMC with FFC can improve students' language learning. The present study gears towards investigating the effect of this integration in enhancing the knowledge of vocabulary among a number of Iranian EFL learners.

\section{LITERATURE REVIEW}

\section{A. Computer Mediated Communication (CMC)}

Communicating using the computer is often referred to as CMC and encompasses communication by email, bulletin boards, and chatlines. Hiltz and Turoff (1978) coined the term CMC although they had a very limited idea about computers at that time. Murray (2000, p. 398) asserts that "their use of the term being confined to this mode of electronic communication. Other researchers include communication via e-mail, bulletin boards, Internet Relay Chat (IRC), e-mail discussion lists, chat rooms, and the World Wide Web." Beatty (2003) holds that CMC refers to a situation in which computer-based discussion may take place but without necessarily involving learning. He adds that "opportunities for learning are inherently present, especially in situations in which learners need to engage in negotiation of meaning with native speakers of the target language or even with peers of non-native proficiency" (Beatty, 2003, p. 62). 
CMC, also called Computer-Assisted Class Discussion (CACD) or Computer-Mediated Discussion (CMD) has been increasingly integrated and used in educational instruction and language learning (Chun, 1994) because it provides opportunities for language learners to practice their language while communicating with people with the mediation of computers (Chanrungkanok, 2004). CMC allows computer users to connect and communicate via the internet with individuals around the world (De la Fuente, 2003).

In $\mathrm{CMC}$, referring to text-based communication, participants interact with each other by typing a message on the keyboard of one computer which is to be read by others on their computer screens, either immediately or after a particular time (Herring, 1996). In this electronic discourse, two or more people can communicate without having to be Face to Face (F2F) and without limitations of time and space (Yang, 2006).

\section{B. Types of $C M C$}

Even though the field of CMC is relatively new, it has been approached by many language researchers and instructors who support the use of computer technology and its potential to extend language teaching within and outside the classroom (Lage, 2008). CMC can be divided into two communicative modes. One is real-time or Synchronous CMC (SCMC), such as Internet Relay Chat (IRC), Instant Messaging as in Yahoo or MSN Messenger, Multi-user domain Object-Oriented (MOO) and audio/video conferencing. The other is delayed time or Asynchronous CMC (ACMC), such as email, web blog, Scientific Interest Groups (SIGs) listserves, newsgroups, and bulletin board.

Synchronous CMC (SCMC). Synchronous or real-time CMC is represented by chatting, audio/video conferencing, and MOOs. According to Anderson and Garrison (2004) synchronous communication is a form of communication where both the sender and receiver of the message are physically or virtually present. Typically, SCMC refers to chat which is defined as "the online interactive exchange of information between two or more participants simultaneously logged on to a computer" (Chanrungkanok, 2004, p. 14).

Synchronous communication is place-independent but not time-independent because participants must be logged on at the same time to communicate with each other (Paulus, 2007). Within educational settings, SCMC creates a less stressful learning environment for shy and anxious students (Yang, 2006), provides more equal participation (Warschauer, 1996), increases students' monitoring of their own and the others' language usage and is not subject to the turn-taking rules of F2F discussion (Warschauer, 1996). People who participate in SCMC discussions not only create more language (Abrams, 2003) but also more complex sentences (Coniam \& Wong, 2004). Furthermore, SCMC can be an excellent medium for prewriting work (Warschauer, 1996) and beneficial for EFL learners to master their language skills as well as their social interaction skills (Chun, 1994). The use of synchronous tools (especially chatting) in educational environments has been investigated by several researchers (Abrams, 2001; Coniam \& Wong, 2004).

Asynchronous CMC (ACMC). The other mode of CMC is Asynchronous CMC (ACMC), such as email, weblog, newsgroups, discussion groups and bulletin boards. This mode of CMC which is delayed time gives the participants the opportunity to communicate with each other by posting their messages. Although with the advent of internet both synchronous and asynchronous CMC have been widely used for communication, in educational settings asynchronous tools are more dominant than synchronous ones (Hsu, Wang, \& Comac, 2008) and have been researched more thoroughly (Paulus, 2007).

Asynchronous tools have been viewed as affording greater opportunity for reflection on one's own ideas, as well as on comments made by others (Paulus, 2007). It has been suggested that ACMC (e.g. email and bulletin boards) promotes the production of more syntactically complex language and more words (De la Fuente, 2003; Abrams, 2003; Zapata \& Sagarra, 2007).

\section{Integration of $C M C$ with FFC}

As Bull and Zakrzewski (as cited in McCarthy, 1999) indicate learning technology is not effective unless it is properly and thoughtfully integrated into the curriculum. Reviewing the literature, Lee (2007) indicates that integrated learning is better and more effective than the traditional classroom type of instruction and individual forms of Elearning technology alone. Also, Meskill and Anthony (2005) suggest that CMC should not serve as a replacement for live instruction, but as a complement to it. As they state "instructor-orchestrated CMC may enhance F2F learning by providing an additional venue to practice and reinforce F2F instruction" (p. 90).

The integration of technology in teaching English as a second/foreign language has been increasing since the 1980s (Warschauer and Whittaker, 2002). Integration of technology into language learning programs needs some ingredients. The five key ingredients in a blended (integrated) learning program identified by Carman (as cited in Lee, 2007) include live events (instructor-led instruction), self-paced learning and assessment, collaboration, and performance support materials.

Warschauer and Whittaker (2002) present some guidelines for teachers who plan to integrate computer technology in their classroom. Theses pedagogical principles include goals, integration, technical support, and learner-centered teaching. As the first thing, they suggest teachers to clarify their goals. Once the instructors had specified the goals and aims, they can design appropriate tasks and activities. In the case of integration, they propose that computer-based activities be integrated into the course curriculum as a whole. In order to avoid problems of technical nature in the classrooms, Warschauer and Whittaker (2002) suggest teachers to provide sufficient technical support for their students. Finally, they state that teachers should provide a learner-centered environment by involving learners throughout the 
entire instructional process.

\section{The PRESENT STUdy}

The present study intends to investigate the possible existence of difference between CMC and ICMC groups, on the one hand, and FFC and ICMC groups, on the other hand, as far as vocabulary language learners' improvement is concerned. For the purpose of this study, the quantitative research methodology was selected to find answers to questions concerning integration of CMC with FFC. Because of the difficulty encountered when attempting to form groups by random assignment, the researcher utilized groups which already existed in classes. Due to the use of preformed groups, the design of this study is quasi-experimental in nature. The present study seeks answer to the following questions.

\section{A. Research Questions}

1) Is there any significant difference between CMC and ICMC groups with respect to language learners' vocabulary improvement?

2) Is there any significant difference between FFC and ICMC groups with respect to language learners' vocabulary improvement?

\section{B. Method}

Participants. The participants in this study consisted of 88 Iranian EFL learners divided into one comparison and two experimental groups. Twenty-nine participants of the comparison group, called FFC group, selected from among intermediate students of language institute in Tabriz, a city in northwest of Iran, only participated in traditional F2F interactions with teacher supervision in the classroom. Upon inclusion in the program, the participants were at the intermediate level. Their proficiency had been determined via the placement test usually administered at the institute. The other option for getting to this level was passing previous levels of English courses usually offered in the institute. It could be inferred that the participants were of the same, or very similar, general English proficiency.

The experimental group consisted of two groups: CMC and Integrated CMC (ICMC) groups. The CMC group was selected from members of online English learning websites. Twenty nine male and female members of online language learning groups took part in this study. Their connection with English was only through online language learning groups and had no F2F interactions. The participants of ICMC group $(n=30)$ were recruited from male and female students at the language institute and benefited from both FFC in the classroom and CMC via language learning websites and groups.

Instruments. Instruments used for collecting data in this study included two tests of lexical knowledge and a questionnaire. All participants of the three groups took two parallel but not identical standardized vocabulary tests which formed a pre-test and a post-test. The two sets of tests included vocabulary items very close in the level of difficulty, number, content, and table of specifications the students had already covered in their language courses. The tests covered a wide range of English words selected and adapted from the intermediate book of Nelson English Language Tests (Fowler \& Coe, 1976) with regard to their frequency in other vocabulary tests and with special attention to include all kinds of parts of speech: verb, noun, adjective, and adverb. Every effort was made to make the two sets of vocabulary tests as similar to each other as possible. Both tests included two sets: 15 Multiple Choice Questions (MCQs) and 5 completion-type items in which the students were required to write synonyms in the spaces provided.

The participants were also requested to fill in a background questionnaire. The questionnaire was adapted from Warner's (2004) student survey to induce information about the students' access to computer/internet and their experience with CMC and was used to assign the students to comparison and experimental groups. It provided useful information about the student's familiarity with communication technology, how well they assessed their computer knowledge and typing abilities, and was used to select the students who had equal access to the internet and equal familiarity with online communication (e.g.: email, blogs, and chatrooms).

Reliability and validity. The current experiment required a pre-test, a post-test and a questionnaire. As with all types of assessment, these tests needed to be reliable and valid. The reliability of the tests were calculated using KR-21 method which equals a modest index of 0.66 for both the pre-test and the post-test. The questionnaire was administered just to collect background information about the participants and was not subject to reliability analysis. Moreover, its reliability had already been established.

In order to examine the validity of instruments, expert review and factor analysis technique was used. To neutralize and reduce the effect of teaching and therefore validating the tests, expert review was used for the tests. Two instructors of intermediate level in the institute were requested to check and confirm the appropriateness of tests for intermediate level and whether there were any items included in the students' course books. In addition, factor analysis was run to examine the construct validity of tests. The results from principal component analysis with varimax rotation method for pre-test showed that factor 1 explained $15.436 \%$ of the total variance, factor 2 explained $11.089 \%$ of the variance, factor 3 explained $9.581 \%$ of the variance, and factor 4 explained $8.610 \%$ of the variance. 
Likewise, the results of principal component analysis for the post-test showed that factor 1 explained $15.866 \%$ of the total variance, factor 2 explained $10.744 \%$ of the variance, factor 3 explained $9.817 \%$ of the variance, factor 4 explained $8.727 \%$ of the variance and factor 5 explained $7.703 \%$ of the variance.

Procedure. The study started at the beginning of the 2008 winter semester and ran for six weeks. At the second session of the semester, the pre-test and the background questionnaire were administered at the three branches of the institute. The pre-test was administered to identify who would qualify to participate in the study. In fact, the pre-test acted both as a criterion and base-line for selecting the students who were approximately at the same level of vocabulary knowledge and as a reference for their improvement after the treatment.

After collecting the data, based on the results of the background questionnaire the students were assigned to either the comparison or the experimental groups. The classes whose students had more access to computer and internet with more experience of working with synchronous and asynchronous CMC were assigned to ICMC group. In the same way, the researchers tried to include the students with little or no access to computer and internet, either at home or elsewhere, in the comparison group. As there were three different branches in different parts of the city, it could be assumed for sure that no contact, whatsoever, existed among the three groups of participants.

In an introduction session, the ICMC participants were familiarized with the project. The initial meeting was organized at each of the three branches focusing on technical training in order to give all participants the opportunity to visit the related websites and chatrooms, to register in the sites and to make their own blogs. The students were told to chat with their peers approximately 15 minutes a day outside the classroom and to contact with their friends via email and their blogs. All participants were encouraged to register in free online English learning websites and to make their own blogs in order to get to know each other, to contact with native and non-native speakers of English and to be acquainted with the synchronous and asynchronous environments.

Having finished the last session of the semester, the participants got ready to take the post-test. The post-test was administered to determine which words were learned after the treatment. The vocabulary items in the post-test were identical to the words in the pre-test with a difference in question form. The reason to choose the same words was to assess how much CMC could assist in the students' learning of those words.

Data analysis. A One-way analysis of variance (ANOVA) was run to analyze the average scores of the three groups' pre-test scores to show group homogeneity. In order to compare the results of the pre-test with those of the post-test, paired samples t-tests were conducted for each group. Independent samples t-tests were also performed to compare the results of the post-test: one between the CMC and ICMC groups and the other between FFC and ICMC. As stated earlier, to examine the construct validity of the tests, expert review and factor analysis techniques were employed for both tests.

\section{RESUlts}

\section{A. Group Homogeneity}

In order to assess the effect of training among the groups of learners, first it was important to establish that the groups started out at more or less the same place (McBride, 2007). The first question to look at in the present study to check homogeneity or what McBride calls "the group equivalence" (p. 122) is whether the pre-test scores of the three groups were more or less similar to each other. To compare the comparison group and the experimental groups, the pre-test scores were subjected to a one way ANOVA. The results of the ANOVA (see Table 1) revealed that the differences among the means were not significant $[\mathrm{F}(2,85)=1.841, \mathrm{p}=0.165]$ and the three groups can be said to be, to a large extent, homogeneous. As a result, the study went on safely with these three groups.

TABLE 1

RESULTS OF ANOVA FOR PRE-TEST AMONG THE THREE GROUPS

\begin{tabular}{|l|l|l|l|l|l|}
\hline & RESULTS OF ANOVA FOR PRE-TEST AMONG THE THREE GROUPS \\
\hline Between Groups & Sum of Squares & df & Mean Square & F & Sig. \\
\hline Within Groups & 17.374 & 2 & 8.687 & 1.841 & .165 \\
\hline Total & 400.990 & 85 & 4.718 & & \\
\hline
\end{tabular}

\section{B. Investigation of Research Question 1}

Research question 1 asked whether there is any significant difference between CMC and ICMC groups regarding their vocabulary improvement. At the first step, a paired samples t-test was carried out to compare the results of the pretest and the post-test in CMC group. This showed a significant difference $[\mathrm{t}=-2.592, \mathrm{p}=0.015]$. Next, another paired samples t-test was carried out between pre-test and post-test results of the ICMC group. Comparison of means in the ttest, again showed a significant difference $[\mathrm{t}=-5.125, \mathrm{p}=0.000]$. Table 2 indicated the summary of the findings.

TABLE 2

PAIRED SAMPLES T-TEST FOR CMC AND ICMC

\begin{tabular}{|l|l|l|l|l|l|l|}
\hline Tests & Groups & Mean & SD & t & df & Sig. (2-tailed) \\
\hline pretest - posttest & CMC & -1.17241 & 2.43588 & -2.592 & 28 & $.015^{*}$ \\
\hline pretest - posttest & ICMC & -2.03333 & 2.17324 & -5.125 & 29 & $.000^{*}$ \\
\hline
\end{tabular}


The descriptive statistics (presented in table 3) for the two groups indicated that both groups improved in vocabulary knowledge. The participants in the CMC group raised their mean score from 12.06 in pre-test to 13.24 in post-test and those in the ICMC group improved from 12.70 to 14.73 .

TABLE 3

DESCRIPTIVE STATISTICS FOR CMC AND ICMC

\begin{tabular}{|l|l|l|l|l|}
\multicolumn{5}{l}{ DESCRIPTIVE STATISTICS FOR CMC AND ICMC } \\
\hline Groups & Tests & Mean & N & SD \\
\hline \multirow{2}{*}{ CMC } & pretest & 12.0690 & 29 & 2.46303 \\
\cline { 2 - 5 } & posttest & 13.2414 & 29 & 3.06658 \\
\hline \multirow{2}{*}{ ICMC } & pretest & 12.7000 & 30 & 1.96784 \\
\cline { 2 - 5 } & posttest & 14.7333 & 30 & 2.40593 \\
\hline
\end{tabular}

In the second step, the post-test scores of CMC and ICMC groups were compared with each other to investigate any difference between the two groups. To accomplish this, an independent samples t-test was conducted. The comparison between post-test scores showed a significant difference between the two groups $[t=2.083, p=0.042]$. Comparing the mean of the two groups in pre-test and post-test, and calculating the gain score of the two groups (1.18 for CMC and 2.03 for ICMC) resulted to the conclusion that ICMC group outperformed the CMC one after the treatment. In addition, it is worth noting that in the post-test, ICMC group, with a standard deviation of 2.40 , performed more homogeneously than CMC group $(\mathrm{SD}=3.07)$. (Table 4).

TABLE 4

INDEPENDENT SAMPLES T-TEST FOR CMC AND ICMC

\begin{tabular}{|l|l|l|l|l|l|l|l|l|}
\hline Test & Groups & N & Mean & SD & F & t & df & Sig. (2-tailed) \\
\hline \multirow{2}{*}{ posttest } & CMC & 29 & 13.2414 & 3.06658 & 2.282 & 2.083 & 57 & .042 \\
\cline { 2 - 6 } & ICMC & 30 & 14.7333 & 2.40593 & & & & \\
\hline
\end{tabular}

\section{Investigation of Research Question 2}

In order to investigate the research question 2 it was hypothesized that there is no significant difference between FFC and ICMC groups with respect to their vocabulary improvement. The procedure for investigating and answering this question was similar to that in research question 1. First, paired t-tests were run to compare the pre-test and post-test scores of FFC and ICMC groups. The results of the paired t-test comparing pre-test and post-test scores showed no significant difference $(\mathrm{p}>0.05)$ in the performance of FFC participants $[\mathrm{t}=-2.006, \mathrm{p}=0.055]$ although they made some gains in their post-test scores (a mean of 0.82 points from 11.62 to 12.44 ). However, as it was discussed in the case of research question 1 , in ICMC group significant $\mathrm{p}$ value $(\mathrm{p}=0.000)$ indicated that there is statistically significant difference between the scores of this group in the two sets of observations. The comparison of paired t-tests between the two groups is presented in tables 5 and 6.

TABLE 5

PAIRED SAMPLES T-TEST FOR FFC AND ICMC

\begin{tabular}{|l|l|l|l|l|l|l|}
\hline Tests & Groups & Mean & SD & t & df & Sig. (2-tailed) \\
\hline pretest - posttest & FFC & -8.2759 & 2.22115 & -2.006 & 28 & 0.055 \\
\hline pretest - posttest & ICMC & -2.03333 & 2.17324 & -5.125 & 29 & 0.000 \\
\hline
\end{tabular}

TABLE 6

DESCRIPTIVE STATISTICS FOR FFC AND ICMC

\begin{tabular}{|l|l|l|l|l|}
\hline Groups & Tests & Mean & N & SD \\
\hline \multirow{2}{*}{ FFC } & pretest & 11.6207 & 29 & 2.06006 \\
\cline { 2 - 5 } & posttest & 12.4483 & 29 & 2.32358 \\
\hline \multirow{2}{*}{ ICMC } & pretest & 12.7000 & 30 & 1.96784 \\
\cline { 2 - 5 } & posttest & 14.7333 & 30 & 2.40593 \\
\hline
\end{tabular}

After estimating the differences between the pre-test and the post-test scores of the two groups independently, an independent samples t-test was conducted to compare and investigate any differences between the two groups in posttest scores. This showed significant difference $(\mathrm{p}=0.000)$ between the two groups in post-test favoring the ICMC group. Given the gain scores of ICMC $(14.73-12.70=2.03)$ and FFC groups $(12.44-11.62=0.82)$, it can be concluded that ICMC outperformed FFC. So, the null hypothesis Ho2 can be rejected again safely. It is worth noting that although FFC group did not improve their vocabulary knowledge significantly, they performed more homogenous $(\mathrm{SD}=2.32)$ than the participants in the ICMC group with a standard deviation of 2.40. (Table 7)

TABLE 7

INDEPENDENT SAMPLES T-TEST FOR FFC AND ICMC

\begin{tabular}{|l|l|l|l|l|l|l|l|l|}
\hline Test & Groups & N & Mean & SD & F & t & df & Sig. (2-tailed) \\
\hline \multirow{2}{*}{ posttest } & FFC & 29 & 12.4483 & 2.32358 & .004 & -3.709 & 57 & .000 \\
\cline { 2 - 5 } & ICMC & 30 & 14.7333 & 2.40593 & & & & \\
\hline
\end{tabular}




\section{CONCLUSIONS AND Discussions}

The purpose of the study was to examine the effect of integrating CMC with FFC on vocabulary improvement. In order to investigate the impact of the treatment, first it was necessary to establish that the three groups began from basically the same starting point. The results of ANOVA comparing the three groups demonstrated that differences among the groups were not significant, meaning that the groups were equivalent to begin with. After a six-week period of treatment and the administration of the post-test, in order to explore the effect of CMC integrated with FFC on the participants' vocabulary improvement, the results of pre-test and post-test scores of the comparison and experimental groups were compared. To investigate the existence of any difference between the CMC and ICMC groups, the results of the pre-test for both groups were compared with their post-test scores. It demonstrated that after the six-week treatment, both experimental groups made some gains in their vocabulary scores. But, the comparison of post-test scores of the two groups, and calculating their gain scores showed that the ICMC group made better progress on the post-test score and outperformed the CMC group after the treatment. In addition, in the post-test the ICMC group participants performed more homogeneously than the $\mathrm{CMC}$ group.

As to assessing the differences between the ICMC and the FFC groups, the participants' pre-test and pot-test scores were compared. The findings suggested that, although FFC participants made some gains in their post-test scores, there was no significant difference in their performance, meaning that they had not improved their vocabulary significantly. Against the FFC group, ICMC participants showed statistically significant improvement in their performance in the two sets of observations. As it was expected, the comparison of the post-test scores clearly showed significant difference between the two groups in post-test favoring the ICMC group. Calculations of the gain scores of the two groups again proved the superiority of the ICMC group over FFC group.

Traditionally, education has always been best realized when the two sides, i.e., the teacher and the students, are feeling the presence of each other. In this context, the teacher can easily and directly monitor the students' improvement and guide them step by step towards perfection. On the other hand, the students find it quite convenient to ask the questions they have from the teacher. This face-to-face atmosphere throughout centuries has brought about good results. However, shortly after computers' entering into human life, firstly as a calculation or computation medium and later as a communication mediator, they found their way in educational settings easily. In a sense, educational systems showed very little resistance due to the convenience of computers. After the advent of internet, computers became an indispensible part of approximately all education centers. Little by little, every individual found it a must to benefit from this new technological advancement.

As far as the employment of computers is concerned, language teaching/learning has never been an exception. Experts started their investigations to delve into the advantages and disadvantages of computers, to see if computer mediated communications can be employed to facilitate teaching a language and to enhance its learning. The present study is more justifiable in that it investigates the combination of so-called traditional method, i.e., face to face interactions between the teacher and the students, and modern computer-mediated communication. As it was hypothesized, it was found that those students who had been using both FFC and CMC were more successful in improving their vocabulary knowledge. This signifies the fact that the integration of the two aforementioned approaches could result in students' better achievement.

Findings of this research support the idea that integration of technology in general and CMC in particular into language teaching environments can assist language learners and teachers in the process of learning and teaching. CMC can be utilized as a tool to enhance communication of learners with native and non-native speakers all around the globe. This communication which leads to negotiation of meaning induces more input and output which consequently leads to more and better learning.

The reasons for this better achievement can be:

1. Language learners find the opportunity to benefit from extracurricular activities besides their regular classroom. They have both the FFC, in which they can communicate with their teachers and peers, and CMC, in which they go beyond classroom boundaries.

2. Through CMC, necessary grounds are provided for language learners to develop interactions with native speakers of English. In that case, they learn the meanings of words in a better way. Moreover they find an opportunity to grasp the true sense of vocabulary items in communications.

3. Those language learners whose learning styles, e.g. introverts, act as a barrier in the process of learning when they are in a classroom situation and find FFC rather difficult in developing communication can benefit from the virtual environment of CMC in expressing themselves and thereby they set out to learn more.

4. When CMC is combined with FFC, it is possible for the learners to resolve their problems they face in CMC within the FFC environment.

\section{REFERENCES}

[1] Abrams, Z., I. (2001). Computer-mediated communication and group journals: Expanding the repertoire of participant roles. System, 29(4), 489-503.

[2] Abrams, Z., I. (2003). The effect of synchronous and asynchronous CMC on oral performance in German. The Modern Language Journal, 87, 157-167. DOI: 10.1111/1540-4781.00184 
[3] Anderson, T. \& Garrison, D., R. (2004). E-learning in the $21^{\text {st }}$ century: A framework for research and practice. London: Routledge Falmer, Taylor and Francis Group.

[4] Beatty, K. (2003). Teaching and researching computer-assisted language learning ( $2^{\text {nd }}$ edn.). New Jersey: Pearson Education.

[5] Chanrungkanok, P. (2004). A naturalistic study of the integration of computer-mediated communication into oral discussion in an EFL college classroom in Thailand. Unpublished doctoral dissertation, Indiana University of Pennsylvania. ProQuest Information and Learning Company. UMI: 3142066.

[6] Chun, D. M. (1994). Using computer networking to facilitate the acquisition of interactive competence. System, 22(1), 17-31.

[7] Coniam, D., \& Wong, R. (2004). Internet Relay Chat as a tool in the autonomous development of ESL learners' English language ability: An exploratory study. System, 32(3), 321-335.

[8] De la Fuente, M. J. (2003). Is SLA interactionist theory relevant to CALL? A study on the effects of computer-mediated interaction in L2 vocabulary acquisition. Computer Assisted Language Learning, 16(1), 47 - 81.

[9] Fowler, W. S. \& Coe, N. (1976). Nelson English language texts. London: Thomas Nelson and Sons Ltd.

[10] Herring, S. (1996). Computer-mediated communication: Linguistic, social and cross-cultural perspectives. Amsterdam: Benjamins.

[11] Hiltz, S. R., \& Turoff, M. (1978). The network nation: Human communication via computer. Norwood, NJ: Ablex.

[12] Hsu, H-Y., Wang, S-K., \& Comac, L. (2008). Using audioblogs to assist English-language learning: An investigation into student perception. Computer Assisted Language Learning, 21(2), 181-198.

[13] Lage, T., M. (2008). An exploratory study of Computer Assisted Language Learning (CALL) glosses and traditional glosses on incidental vocabulary learning and Spanish literature reading comprehension. Unpublished master's thesis, Iowa State University. ProQuest Information and Learning Company. UMI: 1454699.

[14] Lee, T. C. (2007). Using web-based CALL to improve English language mastery at the republic of china air force academy. Unpublished doctoral dissertation, Nova Southeastern University. ProQuest Information and Learning Company. UMI: 3241979.

[15] Levy, M. (1997). Computer-assisted language learning: Context and conceptualization. Oxford: Oxford University Press.

[16] McCarthy, B. (1999). Integration: The sine qua non of CALL. CALL-EJ, Online 1(2). Retrieved from http://www.tell.is.ritsumei.ac.jp/callejonline

[17] Meskill, C., \& Anthony, N. (2005). Foreign language learning with CMC: Forms of instructional discourse in a Hybrid Russian class, System, 33(1), 89-105.

[18] Murray, D. (2000). Protean communication: The language of computer-mediated communication. TESOL Quarterly, 34(3), 397-421.

[19] Paulus, T. (2007). CMC modes for learning tasks at a distance. Journal of Computer-Mediated Communication, $12(4)$, article 9. Retrieved from http://jcmc.indiana.edu/vol12/issue4/paulus.html

[20] Warschauer M. (1996). Computer Assisted Language Learning: An introduction. In Fotos S. (ed.) Multimedia language teaching, Tokyo: Logos International: 3-20.

[21] Warschauer, M., \& Healey, D. (1998). Computers and language learning: An overview. Language Teaching, 31(1), 57-71.

[22] Warschauer, M., \& Whittaker, F. (2002). The internet for English teaching: Guidelines for teachers. In J. Richards \& W. A., Renandya (Eds), Methodology in language teaching: An anthology of current practice (pp. 368-373). Cambridge University Press.

[23] Yang, M., L. (2006). Exploring Taiwanese EFL students' responses to synchronous CMC: Effects on language use, learning and transfer, and perceptions. Unpublished doctoral dissertation, University of Texas. ProQuest Information and Learning Company. UMI: 3267861.

[24] Zapata, G., \& Sagarra, N. (2007). CALL on hold: The delayed benefits of an online workbook on L2 vocabulary learning. Computer Assisted Language Learning, 20(2), 153-171.
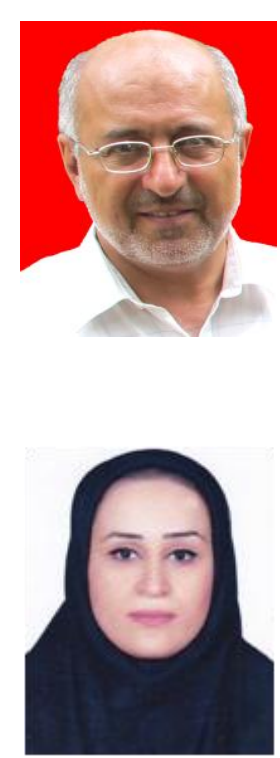

Abbas Ali Rezaee was born in Tehran, IR Iran, in 1956. He finished his MA in Teaching English as a Foreign Language (TEFL) in Tabiat Modarres University, Tehran, in 1989 and obtained his PhD in Applied Linguistics from the University of Exeter, England, in 2001.

$\mathrm{He}$ is currently a member of academic staff at the Department of English Language and Literature, Faculty of Foreign Languages and Literatures, University of Tehran. He has published many articles in national and international journals. He has taught specialized courses at BA, MA and PhD levels and has also supervised a large number of MA theses and $\mathrm{PhD}$ dissertation in language teaching and testing. His main research interests are Language Teaching, Language Testing, Discourse Analysis, ESP, and CALL.

Dr Rezaee is a member of the Teachers of English Language and Literature Society in Iran (TELLSI). He is the reviewer for a number of domestic and international journals.

Solmaz Ahmadzadeh was born in Isfahan, Iran in 1982. She obtained her BA in English Translation from Islamic Azad University of Shahreza, Isfahan, in 2005. In August 2009 she finished her MA in Teaching English as a Foreign Language at the Faculty of Foreign Languages and Literatures, University of Tehran, Iran.

She is currently teaching English in Payame Noor University of Jolfa, Tabriz, and also at Seraj Higher Education Language Institute in Tabriz, Iran.

Mrs Ahmadzadeh's main research interests are 'Language Teaching' and 'Computer Assisted Language Learning (CALL)'. 